\title{
Caecal Volvulus on Complete Common Mesentery: A Case Report
}

Mourad Badri*, Abderrahim AIT Abderrahim, Anas Belhaj, Ahmed Zerhouni, Tarek Souiki, Imane Toughrai, Khalid Mazaz, Karim IBN Majdoub Hassani

Visceral and Endocrinological Surgery Service II, Chu Hassan II, Fes, Morocco

DOI: $10.36347 /$ sjmcr.2020.v08i03.030

| Received: 05.03.2020 | Accepted: 13.03.2020 | Published: 19.03.2020

*Corresponding author: Mourad Badri

Abstract

Case Report

Common mesentery is the persistence of an embryonic anatomical arrangement secondary to an anomaly of rotation of the primary umbilical loop, thus constituting a common meso to the whole intestine and a short root of the mesentery. These intestinal rotation anomalies can lead to tragic and sometimes fatal complications, which generally occur during the neonatal period or at pediatric age. It is estimated that the prevalence of these congenital malformations in adulthood is around $0.2 \%$ to $0.5 \%$ at which age they very often remain asymptomatic and therefore undiagnosed (1). The diagnosis of total volvulus of the small intestine could be made in very varied circumstances: in emergency in front of a table of acute intestinal obstruction, even a state of shock, in front of a table of abdominal pain repeated more or less associated with transit disorders. We report the observation of a 21 -year-old patient admitted for total volvulus of small hail on a complete common mesentery in which the evolution was favorable.

Keywords: Complete common mesentery, adult, volvulus.

Copyright @ 2020: This is an open-access article distributed under the terms of the Creative Commons Attribution license which permits unrestricted use, distribution, and reproduction in any medium for non-commercial use (NonCommercial, or CC-BY-NC) provided the original author and source are credited.

\section{INTRODUCTION}

Common mesentery results from an abnormality in the rotation of the digestive tract. It is characterized by the persistence of an embryonic anatomical arrangement secondary to an abnormal rotation of the primary umbilical loop, with a common meso to the entire intestine and a short root of the mesentery [2]. This insufficient rotation is most often associated with a lack of attachment. What makes this pathology exceptional in adulthood is that its symptomatology, quite heterogeneous, is a source of many errors and diagnostic and therapeutic delay to the point that many cases are diagnosed in post-mortem. The causes of his late disclosure are still unknown. The most dreadful complication is the total volvulus of the small intestine, it occurs when the type of the anomaly of rotation is an incomplete common mesentery at $180^{\circ}$ rarely for the complete common mesentery [3].

\section{CASE RePORT}

We report the observation of a 21 years old young man, suffering from a non-explored motor disability of the 2 lower limbs since childhood, and whose mother was operated for occlusion over a volvulus of the small intestine on common mesentery. This young male was admitted in our night shift in an acute intestinal occlusion table; the symptomatology had evolved for more than 48 hours before his admission, made of abdominal pain of rapidly progressive intensity with vomiting initially alimentary then bilious, evolving in a context of apyrexia and deterioration of the general state.

The patient was shocked with blood pressure at $80 \mathrm{mmHg} / 50 \mathrm{mmHg}$; a heart rate of 100 beats / min; polypneic at 22 cycles / minutes; apyretic, and dehydrated. The abdominal examination found a much distended tympanic abdomen, the ganglionic areas were free and the rectal examination finds an empty rectal bulb.

After the conditioning (Monitoring, oxygen therapy, fixing up of gastric and bladder tubes) we could notice that he was anuric and had important gastric stasis; he benefited from a vascular filling with physiological saline serum $20 \mathrm{cc} / \mathrm{kg}$ in 30 minutes and we carried out a biological and radiological assessment. The Biological assessment found a Hyperleukocytosis at 18000 elements / $\mathrm{mm} 3$ predominantly PNN with a correct renal function, the C-reactive protein was at 235 $\mathrm{mg} / \mathrm{l}$. the abdomen x-ray found out hydro-aeric colic and grelic levels, with significant colonic distension. Abdominal CT scan revealed a distension of right colon and half of transverse colon with hydro-airic content up to $10 \mathrm{~cm}$ in the cecum, upstream of a swirl image on the 
left part of transverse colon. The scan also identified an anomaly of anatomical arrangement of the organs (cecum at the hypogastric region and the small bowel occupying almost the entire right part of the abdomen.

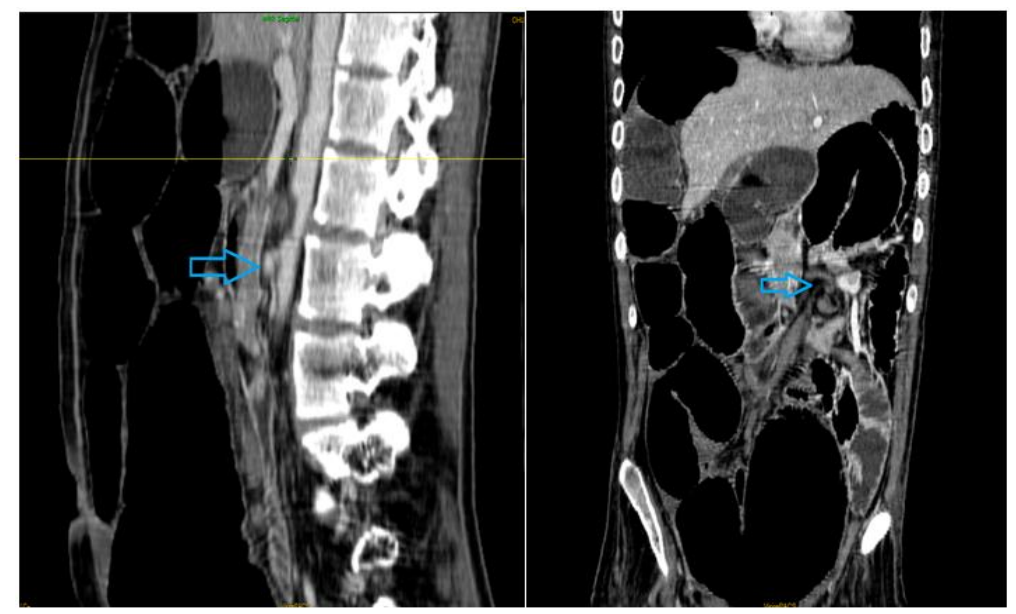

Left: CT image showing the third portion of the duodenum not included in the arterial clamp. Right: swirl image of the volvulus

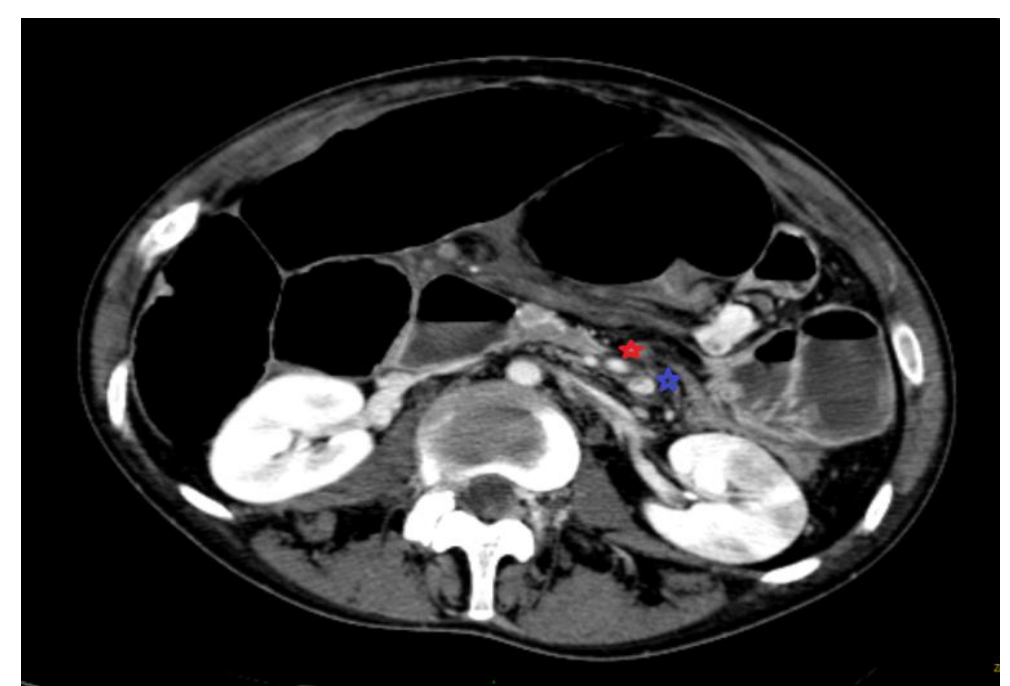

CT image showing transposition of the superior mesenteric artery (in red) and vein (in blue), characteristic of the common mesentery

The diagnosis of occlusion on a complete common mesentery confirmed and the patient was urgently admitted to the operating room under antibiotic coverage.

We approached through a mid-pubic incision. The exploration revealed a distended and distressed small bowel, occupying the right part of the abdominal cavity. We also found out that the caecum was in a hypo-gastric situation and much distended with a necrotic, in pre-perforation wall. The externalization of the small intestine objectified a twist of the small intestine and cecum around the vascular mesenteric axis, and the duodeno-jejunal angle was on the right side of the median line (fig 3). The intraoperative aspect was in favor of a total volvulus of the small bowel and cecum on complete common mesentery.

The gesture consisted of a release of the small intestine in a counterclockwise direction, which allowed its revascularization and return to its normal coloration in a few minutes. A right hemi colectomy was carried out taking away the right colon and the necrotic part of the small intestine, then we completed the cure for the rotation anomaly according to the LADD procedure, and finally we performed a Bouilly-Wolkmann double stomy. 


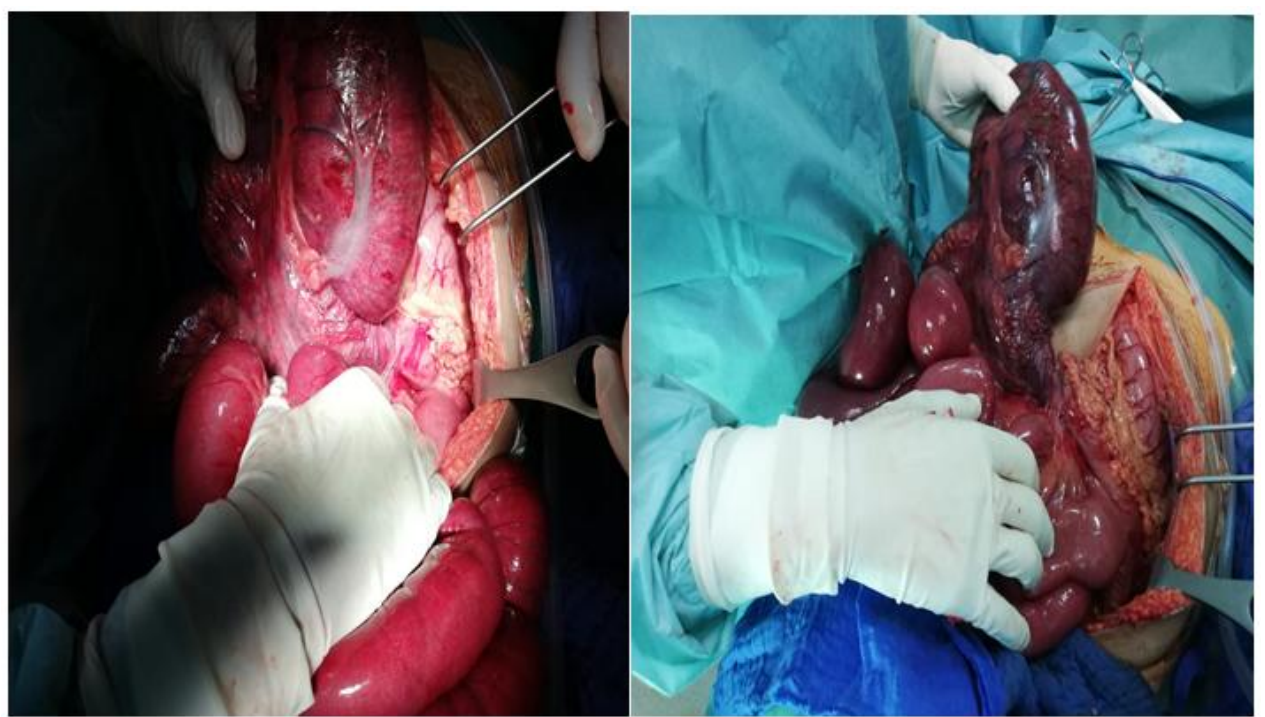

Left: caecum incarcerated in the vortex of the volvulus, with ischemic wall. Right: cecum after devolvulation.

The patient was extubated in intensive care after hemodynamic stability. The postoperative course was favorable.

\section{DISCUSSION}

The rotation stop of the yolk loop at 90 degrees makes the complete common mesentery with a colon located on the left, mesentery and small bowel on the right; wich is the case of our patient. The most frequent form of intestinal rotation anomalies is the incomplete common mesentery that corresponds to a stop of the yolk loop at $180^{\circ}$ and the cecum comes to join in the sub-hepatic region, which explains the higher risk of volvulus [4]. The caecum is, in frequency, the second part of the colon concerned by the volvulus after the sigmoid and before the left angle and the transverse colon [5].

The mechanism of the volvulus is affected by two main factors: the pivot to the caecal rotation with type of bridles secondary to an inflammatory or postoperative condition, and the caecal distension (Gravity, childbirth, genital tumors, obstacles on the downstream colon, chronic constipation) [6]. The persistence of the primary common mesentery in adults is often well tolerated but can rarely be responsible for volvulus [7].

It only affects $0.2 \%$ to $0.5 \%$ of the total adult population and is generally asymptomatic. $85 \%$ of common mesenteries are diagnosed during the first two weeks of life. Few studies on late acute complications in adults have been described in the literature [8]. In adults, the diagnosis may be fortuitous during radiological examinations or revealed during an appendectomy procedure for ectopic appendix [10]. The difficulty of the diagnosis is explained by the nonspecific symptomatology.
The cecum volvulus produces a clinical table of acute intestinal obstruction by strangulation with pain such as peri-umbilical cramps, rarely under the hepatic or right iliac muscles. The vacuity of the right iliac fossa and the rectal bulb is found in 36 to $76 \%$ [47, 9-11].

An x-ray of the abdomen can help diagnose more than half of the cases; it may show a large hydroaeric level reflecting the distension of the cecum, that could be median, lateralized to the right or to the left. In $50 \%$ we notice an image in "coffee bean" or in "drop of tear". The enema with water-soluble products shows total colonic opacification, and an absence of cecal opacification, with the product being stopped in a "bird's eye view". The CT-scan shows a pathognomonic image in caecal "swirl" with a hypo dense zone which corresponds to the starting point of the twist. The treatment is based on three elements: reducing torsion, treating progressive complications and preventing recurrences. It is essentially surgical using the conservative technique LADD procedure (detorsion, cecopexy by fixing the cecum to the posterior peritoneum) [8]. Endoscopic treatment is not of much interest, with a failure rate exceeding $75 \%$ of cases, but it could be attempted in the event of a countreindication to surgery or in risky areas (pregnancy) [12].

\section{Conclusion}

The occurrence of an acute accident of cecum volvulus on a common mesentery in adults is rare but possible especially in the presence of malformation syndrome and family history. The clinical symptomatology has no specificity. Diagnostic difficulties should, in no case, delay the operative procedure. 


\section{REFERENCES}

1. Incomplete small bowel volvulus on common mesentery--a severe and rare complication in adults: report of one case]. Coulibaly $M$, Boukatta B, Derkaoui A, Sbai H, Ousadden A, Kanjaa N Pan Afr Med J. 2015; 20():157.

2. Plouard C, Rivoal E, Broussine L, Blondin G, Trellu X. Volvulus du grêle sur mésentère commun : Intérêt de l'échographie doppler : à propos d'un cas. J Radiol. 2000; 81(2): 151- 153.

3. Peycelon M, Kotobi H. Complications des anomalies embryologiques de la rotation intestinale: prise en charge chez l'adulte. EMC Techniques chirurgicales - Appareil digestif. 2012 ; 7(4) : 1-12.

4. Zerouali N, Touzani K, Elfares F, Lamhamedi A, Bellakhdar A, Abi F. Volvulus du colon droit et mésentère commun chez l'adulte. J Chir. 1985 ; 122 : 473-7.): 220-4.

5. Abita T, Lachachi F, Durand-Fontanier S, Maisonnette F, Roudaut PY, Valleix D, Descottes B. Les volvulus du cæcum. J Chir. 2005; 142(4) : 220-4.
6. Bougtab A, Amraoui M, Benchekroun BA. Volvulus du coecum. Médecine du Maghreb. 1996 ; $56: 6-8$.

7. Jarry J, Razafindratsira T, Bodin R, Lepront D, Durand-Dastes F. A propos d'un cas de mésentère commun complet de l'adulte révélé par une complication occlusive. Press Med. 2008; Tome 37 (11): 1689-92.

8. Plouard C, Rivoal E, Broussine L, Blondin G, Trellu X. Volvulus du grêle sur mésentère commun : Intérêt de l'échographie doppler. A propos d'un cas. J Radiol. 2000; 81: 151-3.

9. Rousset J. Accident dus aux défauts de rotation de l'anse ombilicale primitive. Mémoires de l'academie de chirurgie. $1955 ; 81: 477-81$.

10. Sarazin R, Voisin R, Sarroste J, Manabie B. Mésentérium commune découvert chez l'adulte à l'occasion d'une appendicite aigue. Journal de médecine de Bordeaux. 1967; 144 : 1556-61.

11. Anderson R, Lee D. Acute coecal volvulus. Br J Surg. 1980; 67: 39-41.

12. Anderson JR, Welch GH. Acte volvulus of the right colon: an analysis of 69 patients. World J Surg. 1986; 10: 336-42. 